\title{
Édith Fagnoni et Jérôme Lageiste (dir.), L'Événementiel et les villes touristiques
}

Bulletin de l'Association des géographes français, $n^{\circ} 2009-3$, septembre 2009, 120 pages

\section{Léopold Lucas}

\section{CpenEdition}

\section{Journals}

Édition électronique

URL : http://journals.openedition.org/tourisme/346

DOI : 10.4000/tourisme.346

ISSN : 2492-7503

Éditeur

Éditions touristiques européennes

Édition imprimée

Date de publication : 1 juin 2010

Pagination : 90-91

ISSN : 2109-5671

\section{Référence électronique}

Léopold Lucas, «Édith Fagnoni et Jérôme Lageiste (dir.), L'Événementiel et les villes touristiques », Mondes du Tourisme [En ligne], 1 | 2010, mis en ligne le 30 septembre 2015, consulté le 22 septembre 2020. URL : http://journals.openedition.org/tourisme/346 ; DOI : https://doi.org/10.4000/tourisme. 346

Ce document a été généré automatiquement le 22 septembre 2020.

\section{$\theta \Theta \Theta \Theta$}

Mondes du tourisme est mis à disposition selon les termes de la licence Creative Commons Attribution - Pas d'Utilisation Commerciale - Pas de Modification 4.0 International. 


\section{Édith Fagnoni et Jérôme Lageiste (dir.), L'Événementiel et les villes}

\section{touristiques}

Bulletin de l'Association des géographes français, $n^{\circ} 2009-3$, septembre 2009, 120 pages

\section{Léopold Lucas}

\section{RÉFÉRENCE}

Édith Fagnoni et Jérôme Lageiste (dir.), "L'événementiel et les villes touristiques", Bulletin de l'Association des géographes français, n² 2009-3, septembre 2009.

1 Intitulé "L'événementiel et les villes touristiques", le Bulletin de l'Association des géographes français de septembre 2009 fait suite au colloque organisé en décembre 2008 autour du même thème. Composé d'une douzaine d'articles courts mais denses, essentiellement développés à partir d'études de cas riches et variées, ce numéro fait état de l'importance, de plus en plus prépondérante, de l'événementiel dans la construction touristique des métropoles.

2 L'événementiel n'est pas un fait nouveau dans la ville. Il fait même partie de son essence, à l'instar des expositions universelles $\mathrm{du} \mathrm{xx}^{\mathrm{e}}$ siècle, comme le souligne, au détour de son argumentation sur l'événementiel dans la ville des 24 Heures, Luc Gwiadzinski. Cependant, dans un contexte de concurrence mondiale entre les lieux, l'événementiel devient, notamment pour les métropoles, un enjeu véritable, tant pour enrichir et diversifier les pratiques touristiques possibles que pour participer au développement de projets urbains, avec parfois l'émergence de situations originales, telle celle décrite par Jérôme Lageiste concernant le Vendée Globe, avec la mise en place d'un village aux Sables-d'Olonne et l'installation du PC de commandement au pied de la tour Montparnasse, à Paris. 
C'est en effet sur les événements qui, bien qu'éphémères, "laissent des traces dans l'espace" que se focalise avant tout l'attention des auteurs au travers d'exemples d'envergure variable allant de l'échelle locale ou nationale ( $c f$. l'exemple des "Fridays off the 405" du Getty Center à Los Angeles, par Pablo Fuentenebro) à l'échelle internationale, avec notamment la thématique récurrente des Jeux olympiques. Ces derniers sont notamment l'objet central de Stéphanie Beucher qui s'interroge ainsi sur la relation existant entre le renouvellement urbain annoncé comme "durable" de Londres et l'organisation d'un tel événement, par essence non durable. L'aspect positif des Jeux olympiques est également relativisé dans le texte de Florence Smits sur Montréal, qui indique que la ville a mis plus de trente ans à payer la dette de l'emprunt nécessaire à la construction du stade olympique, et dans celui de Jean-Pierre Augustin, qui rappelle les mutations extrêmes de Pékin à l'occasion des JO, avec notamment le déplacement de 300000 personnes et la destruction du "patrimoine historique". Le lien avec la dimension patrimoniale de l'urbain est d'ailleurs souvent établi; c'est notamment le cas dans la contribution de Maria Gravari-Barbas à propos de la ville festive.

4 Il est intéressant de remarquer que l'événement, souvent conçu comme facteur de distinction, peut, en cas de succès, connaître une large diffusion et devenir un modèle, comme l'explique Édith Fagnoni à propos de Paris Plages. Et s'il est initialement provisoire, momentané, il est de plus en plus pensé avec l'objectif d'être pérennisé, comme le pointent Jean-René Morice et Philippe Violier. Puissant vecteur de rénovation urbaine, comme en atteste l'exemple de Gênes qui, après une période de crise, connaît un regain certain (Sébastien Jacquot), l'événement doit son succès et sa pérennité, toujours selon Jean-René Morice et Philippe Violier, à l'indispensable adhésion des habitants au projet, ainsi qu'à celle des commerçants, qui peuvent former une coalition pour "sauver" un événement (cf. le Grand Prix de Formule 1 à Montréal, par Florence Smits).

5 Ce numéro offre ainsi une porte d'entrée solide à l'étude d'un phénomène qui, tout en "défaisant la ville" par une "sortie de l'ordinaire", est également un moyen de "faire la ville". De ce point de vue, on peut d'ailleurs regretter l'évocation (même lapidaire) à plusieurs reprises du concept d"'hétérotopie" que Foucault emploie pour distinguer des “espaces autres" : l'objectif de l'événement n'est justement pas de créer ce type de lieu. En effet, s'il concerne globalement moins les touristes à proprement parler que les excursionnistes, l'événement se révèle être un puissant moyen de légitimation des projets urbains. Par ailleurs, si ce bulletin affiche explicitement son ambition de fournir une compilation d'études de cas, on peut regretter l'absence (à l'exception de la tentative typologique de Monica Miranda et Eva Cermakova) d'un développement plus approfondi de la dimension théorique et conceptuelle. Ce bulletin nous invite finalement à poursuivre la réflexion à la fois sur les nombreuses logiques restant encore à comprendre, mais également sur des aspects ou des types d'événement (Carnaval, Gay Pride, etc.) qui n'ont pas été abordés mais dont l'importance est tout aussi remarquable dans la construction touristique de la métropole. 